REVISTA

INTERDISCIPLINAR DE PESQUISA EM ENGENHARIA

\title{
Caracterização da resistência ao desgaste da liga de alumínio SAE 305 após processo de anodização
}

\author{
M. S. T. Pires ${ }^{1}$, T. Doca ${ }^{2}$, V. F. Steier ${ }^{3}$, W. M. da Silva Jr ${ }^{4}$, M. M. de Oliveira Jr ${ }^{4}$ \\ 1. Departamento de Engenharia Mecânica, Instituto Federal de Goiás (IFG), Goiânia, Brasil, email: \\ michel.pires@ifg.edu.br \\ 2. Departamento de Engenharia Mecânica, Universidade de Brasília (UnB), 70910-900, Brasília-DF, Brasil \\ 3. Departamento de Engenharia Automotiva, Universidade de Brasília (UnB), 72444-240, Gama-DF, Brasil \\ 4. Departamento de Engenharia Mecânica, Universidade Federal de Uberlândia (UFU), 38400-902, Uberlândia- \\ MG, Brasil
}

\begin{abstract}
Resumo.
A baixa dureza e resistência ao desgaste do alumínio e suas ligas são fatores de restrição à aplicação dos mesmos. No entanto, nas últimas décadas, vários tratamentos superficiais têm sido desenvolvidos possibilitando diversificar a aplicabilidade das ligas de alumínio, notadamente nas indústrias automotiva e aeroespacial. O presente trabalho pretende estudar o comportamento da Anodização sobre a resistência ao desgaste superficial da liga de alumínio SAE 305. O estudo comparativo foi realizado através de ensaios de desgaste por deslizamento recíproco, na configuração esfera-sobre-plano. Para todos os ensaios foi adotada uma carga normal de contato de $10 \mathrm{~N}$, com uma faixa de deslocamento de $4 \mathrm{~mm}$, uma frequência de oscilação linear de $8 \mathrm{~Hz}$, e dois tempos de duração de ensaio (30 minutos e 60 minutos). O desgaste das amostras foi mensurado através da perda volumétrica utilizando microscopia confocal de varredura a laser. Os resultados mostraram que as amostras da liga de alumínio anodizado tiveram suave aumento na resistência em relação às amostras sem revestimento. Os resultados foram discutidos em termos dos mecanismos de desgaste, que foram caracterizados através de análise utilizando microscopia confocal de varredura a laser.
\end{abstract}

Palavras-chave: Resistência ao desgaste, Liga de alumínio SAE 305, Alumínio anodizado. 


\begin{abstract}
.
The low hardness and wear resistance of aluminum alloys has restricted their application. These alloys require surface treatments or coatings to improve their mechanical strength and tribological properties. This work aims to study the wear behavior of the anodized coatings on the aluminum alloy SAE 305. Reciprocating sliding wear tests using a sphere-on-flat configuration were performed under a normal load of $10 \mathrm{~N}$; a stroke of $4 \mathrm{~mm}$; a frequency of 8 $\mathrm{Hz}$ and two time durations (30 minutes and 60 minutes). The wear resistance of the specimens was evaluated in terms of the volume loss using confocal laser microscopy. In comparison to the untreated aluminum alloy, the anodization process showed a small improvement. The results were discussed in terms of wear mechanisms, which were characterized using confocal laser microscopy.
\end{abstract}

Keywords: Wear resistance, SAE 305 Aluminum alloy, Anodized aluminum. 


\section{Introdução}

Nas últimas décadas, o alumínio e suas ligas tem sido amplamente empregados em várias áreas da engenharia em razão das suas propriedades físicas, tais como: baixo custo de produção e manufatura, boa condutividade termoelétrica, boa resistência contra corrosão, baixa densidade, dentre outros $[1,2]$. No entanto, mesmo com essas vantagens, o uso do alumínio e suas ligas se torna limitado em diversas aplicações em função da sua baixa dureza e características tribológicas deficientes como, por exemplo, a baixa resistência ao desgaste [3].

Um exemplo de aplicação onde componentes de alumínio estão sujeitos a desgaste mecânico é o cabo condutor de energia elétrica. Os cabos condutores são geralmente confeccionados de fios de liga de alumínio encordoados concentricamente. Os danos nos cabos condutores ocorrem como consequência da ação contínua do vento no cabo aéreo tensionado induzindo ao roçamento entre os fios do condutor e destes com o grampo de suspensão, que fixa o cabo condutor às torres de transmissão. Esse fenômeno geralmente leva à perda de material do conjunto cabo/grampo de suspensão, e compromete de modo significativo a vida dos cabos condutores de eletricidade $[4,5]$.

As modificações superficiais tem sido uma alternativa barata e eficiente para melhorar o comportamento tribológico do alumínio e suas ligas, proporcionando um aumento da sua aplicabilidade, especialmente nos setores automotivo e aeroespacial. Várias engenharias de superfície tem sido propostas e estudadas com o propósito de melhorar a resistência ao desgaste e as características friccionais do alumínio e suas ligas como, por exemplo: a anodização, os tratamentos térmicos e as técnicas de revestimento [6, 7].

A oxidação anódica (popularmente conhecida como anodização) tem sido uma técnica tradicional de modificação superficial do alumínio e suas ligas por mais de duas décadas [8]. A anodização caracteriza-se como um processo eletroquímico, que gera um filme superficial de óxido pela transformação do alumínio e alumina. É importante ressaltar que o processo de anodização do alumínio não envolve deposição de material como ocorre nos processos galvanoplásticos. Como alumínio anodizado vários estudos tem reportado um aumento na resistência ao desgaste e à abrasão em diversas aplicações [9, 10]. Dessa forma, a técnica da anodização tem sido adotada em vários setores da engenharia, principalmente nas indústrias aeroespacial e automotiva [11, 12].

No entanto, vários fatores devem ser considerados na escolha de uma técnica de modificação superficial, ou um revestimento, para uma determinada aplicação. É importante ressaltar, primeiramente, que não há um processo universal de escolha da engenharia de superfície que 
satisfaça a todas as condições de uso do material. A escolha da engenharia de superfície mais adequada para determinada aplicação dependerá do estudo de todas as variáveis envolvidas na aplicação do material. Dessa forma, deve-se analisar as condições de operação do material em campo, tipo de material e estado superficial do substrato, custo, carregamentos a que o material estará submetido, efeitos do ambiente sobre o material, dentre outros [13].

Portanto, o objetivo deste trabalho é investigar a eficácia de dois revestimentos superficiais, nomeadamente o DLC e a anodização, contra o desgaste utilizando como substrato a liga de alumínio SAE 305. Para a realização do estudo foram adotados ensaios de desgaste por deslizamento alternado, do tipo esfera-sobre-plano. A marcas de desgaste foram examinadas com microscópio confocal de varredura a laser para medir o desgaste volumétrico, calcular a taxa de desgaste, e identificar os mecanismos envolvidos na remoção de material.

\section{Materiais e métodos}

A liga de alumínio SAE 305 é geralmente adotada para componentes de sistemas de transmissão de energia. Um desses componentes é o grampo de suspensão, que fixa o cabo condutor de energia às torres de transmissão. Como já mencionado anteriormente, a excitação eólica do cabo aéreo tensionado induz ao deslocamento relativo dos fios do cabo entre si e destes com o grampo de suspensão, levando à perda de material de forma mais intensa no interior do grampo. Este fenômeno é chamado de fadiga por fretting [4]. Dessa forma, adotou-se a liga de alumínio SAE 305 como material de base para estudar a eficácia da anodização como revestimento superficial. A Tabela 1 apresenta a composição química da liga de alumínio SAE 305 fornecida pelo fabricante.

Tabela 1: Composição química da liga de alumínio SAE $305 \mathrm{em} \%$.

\begin{tabular}{|l|l|l|l|l|l|l|l|}
\hline Material & $\mathrm{Al}$ & $\mathrm{Si}$ & $\mathrm{Fe}$ & $\mathrm{Zn}$ & $\mathrm{Mn}$ & $\mathrm{Cu}$ & $\mathrm{Mg}$ \\
\hline SAE 305 & 86.0 & 12.0 & 0.5 & 0.35 & 0.35 & 0.25 & 0.1 \\
\hline
\end{tabular}

As amostras de substrato foram confeccionadas em formato cilíndrico com um diâmetro de 10 $\mathrm{mm}$ e altura de $4 \mathrm{~mm}$. Para garantir a homogeneidade da rugosidade na superfície do substrato, todas as amostras foram polidas até uma rugosidade final aproximada de $1.16 \mu \mathrm{m}$. As medições de rugosidade foram feitas utilizando um rugosímetro (Stylus), e utilizando um comprimento de amostragem (cut-off) de $0.8 \mathrm{~mm}$ para todas as medições.

Para os testes de dureza foi adotada a técnica de nanoindentação (Nanoindentator Fisher). A motivação para a escolha da nanoindentação se deve ao fato de que outros métodos de medição 
da dureza perfurariam o revestimento superficial das amostras e, consequentemente, conduziria a um erro na leitura da dureza da camada de revestimento. Foi utilizado um indentador Vickers com força máxima de $300 \mathrm{mN}$, intercalados por um período constante de $30 \mathrm{~s}$ em cada indentação. Os carregamento e descarregamentos foram realizados com um tempo constante de $5 \mathrm{~s}$. Foram realizadas dez medições de dureza em cada amostra, nas mesmas condições, com o intuito de avaliar o desvio padrão dos resultados.

Para realizar a anodização, as amostras foram imersas em um banho eletrolítico composto por ácido sulfúrico (18\%), ácido oxálico (1\%), e uma quantidade significativa de água (81\%) para que, através de reação de eletrólise, ocorra a transformação do alumínio em óxido de alumínio (alumina) na superfície das amostras. Foi aplicada uma voltagem de $18 \mathrm{~V}$ e uma corrente de $1.2 \mathrm{~A} / \mathrm{m}^{2}$ para acelerar o processo de oxidação. A temperatura do banho de anodização foi mantida constante a $18^{\circ} \mathrm{C}$.

Os ensaios tribológicos foram realizados nas instalações do Laboratório de Tribologia e Materiais (LTM), da Universidade Federal de Uberlândia (UFU), em um tribômetro universal da Plint \& Partners, modelo TE 67. Os ensaios no tribômetro foram do tipo deslizamento recíproco, e na configuração esfera-sobre-plano. Esse tribômetro possui uma célula de carga para a medição da força de atrito. Além disso, foi incorporado ao tribômetro um sensor LVDT para a medição da posição da amostra em relação ao contra-corpo em cada ciclo do movimento alternado durante o ensaio. A aquisição dos dados foi feita por uma placa de aquisição ligada a um microcomputador com o software LabVIEW, no qual foi implementado um programa para o tratamento dos dados adquiridos. A fig. 1 mostra a disposição das partes do tribômetro utilizado neste trabalho.

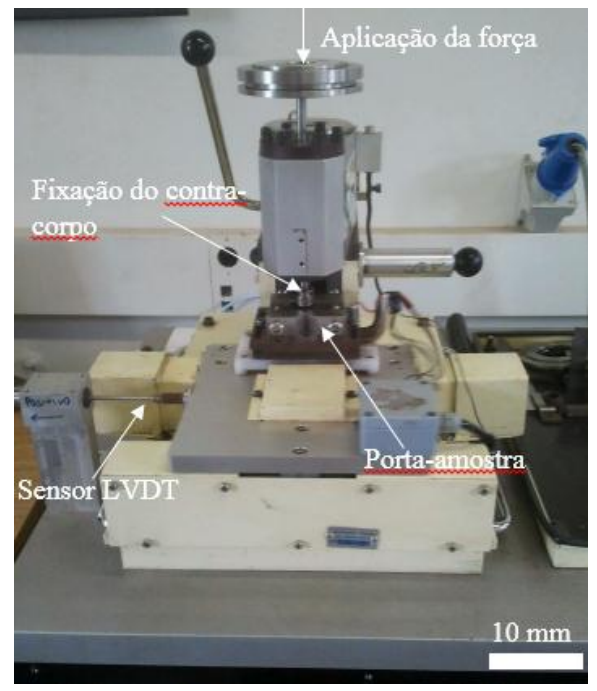

Figura 1: Imagem do tribômetro Plint TE67 utilizado nos ensaios de desgaste. 
Os testes tribológicos foram divididos em duas séries tendo como variável o tempo de duração dos ensaios, sendo que, na primeira série, os ensaios tiveram tempo de duração de 30 minutos e, na segunda série, os ensaios tiveram duração de 60 minutos. Em cada série de ensaios foram realizados dois testes em cada amostra. O comprimento da marca de desgaste foi de $4 \mathrm{~mm}$, a frequência foi de $8 \mathrm{~Hz}$ e a carga normal de contato foi de $10 \mathrm{~N}$, sendo que tais parâmetros foram análogos e mantidos constantes nas duas séries de ensaios. Os testes foram conduzidos com controle de umidade $(50 \%)$ e de temperatura $\left(22 \pm 4^{\circ} \mathrm{C}\right)$, e sem lubrificação.

Como contra-corpo foram utilizadas esferas de aço AISI 52100 de $10 \mathrm{~mm}$ de diâmetro. Sua composição química é apresentada na Tabela 2, conforme informado pelo fabricante. Para cada ensaio foi utilizada uma esfera nova, devidamente limpa com acetona e seca com ar quente. A esfera foi montada de forma que nenhum movimento fosse possível (rolamento ou no plano horizontal). Essa esfera foi apoiada sobre a amostra com carga conhecida, sendo esta aplicada colinearmente ao eixo de simetria da esfera. Durante os ensaios, o deslocamento da esfera foi linear e alternado, com frequência e curso fixos.

Tabela 2: Composição química do aço $52100 \mathrm{em} \mathrm{\% .}$

\begin{tabular}{|l|l|l|l|l|l|l|l|}
\hline Material & $\mathrm{Fe}$ & $\mathrm{Cr}$ & $\mathrm{Mn}$ & $\mathrm{Si}$ & $\mathrm{C}$ & $\mathrm{P}$ & $\mathrm{S}$ \\
\hline 52100 & 96.908 & 1.49 & 0.32 & 0.27 & 0.994 & 0.013 & 0.005 \\
\hline
\end{tabular}

Para a medição do volume de desgaste das amostras ensaiadas foi utilizado o microscópio confocal de varredura a laser (Lext/Olympus). Utilizando os recursos do software do equipamento foi possível inicialmente obter imagens bidimensionais e tridimensionais da marca de desgaste. A partir de tais imagens foi possível realizar um tratamento da imagem através de uma escala de cores possibilitando uma melhor análise da topografia da marca de desgaste. A fig. 2 apresenta a imagem de uma marca de desgaste após o tratamento através de escala de cores. Observando a escala de cores pela fig. 2.a, percebe-se que para as cores mais frias (tons de azul e verde) a profundidade da marca de desgaste é maior. Já as cores mais quentes (tons de amarelo e vermelho) referem-se aos níveis mais próximos à superfície da amostra.

O volume da marca de desgaste foi medido utilizando um plano longitudinal de referência e um plano transversal à marca de desgaste, sendo ambos gerados pelo software do microscópio confocal. A fig 2.b ilustra o método de medição do volume de desgaste em uma das amostras ensaiadas. A região preenchida (cor rosa) corresponde ao volume de desgaste. 
(a)

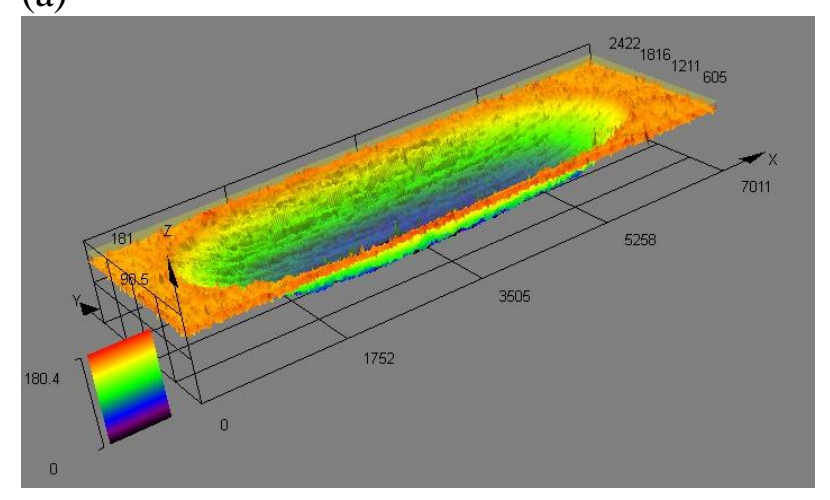

(b)

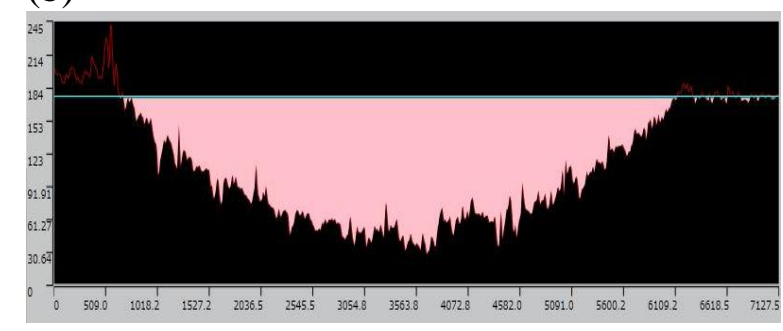

Figura 2: Imagens de marcas de desgaste: (a) image 3D de uma marca de desgaste (b) perfil transversal de uma marca de desgaste utilizado para medir o volume de desgaste.

Uma vez mensurado o volume de desgaste, a equação de Archard foi utilizada para calcular a taxa de desgaste de todas as amostras estudadas [14]. De acordo com Archard, a taxa de desgaste pode ser calculada pela razão do volume removido $(V)$ pelo produto da distância de deslizamento $(S)$ e a carga normal aplicada $(N)$.

$$
\kappa=\frac{V}{S N}
$$

Finalmente, os mecanismos de desgaste das amostras foram analisados através da microscopia confocal de varredura a laser das marcas de desgaste geradas nos ensaios.

\section{Resultados}

Tendo em vista a influência da rugosidade sobre a resistência ao desgaste, o efeito do revestimento sobre a rugosidade superficial foi mensurado neste trabalho. A Tabela 3 apresenta os valores médios do parâmetro $\mathrm{R}_{\mathrm{a}}$ das rugosidades superficiais das amostras ensaiadas.

Tabela 3: Rugosidade média de cada amostra.

\begin{tabular}{|l|c|c|}
\hline Superfícies & Alumínio sem revestimento & Alumínio anodizado \\
\hline Ra $[\mu \mathrm{m}]$ & 0.155 & 1.075 \\
\hline Desvio-padrão $[\mu \mathrm{m}]$ & 0.029 & 0.371 \\
\hline
\end{tabular}

Pela Tabela 3 pode-se observar que as amostras anodizadas tiveram a sua rugosidade superficial aumentada em quase 7 vezes.

A dureza é outro importante parâmetro tribológico de forte influência na resistência ao desgaste. A profundidade de penetração das partículas abrasivas na interface de contato depende da 
dureza do material. No entanto, além da dureza, outros fatores influenciam na resistência ao desgaste do material, tais como: a rugosidade, a tenacidade a fratura, a capacidade de deformação, dentre outros. Portanto, a dureza, como parâmetro único e isolado, não é capaz de predizer a resistência ao desgaste de um material [15]. A Tabela 4 mostra os valores médios de nano-dureza dos espécimes deste trabalho.

Tabela 4: Nano-dureza das amostras.

\begin{tabular}{|l|c|c|}
\hline & Alumínio sem revestimento & Alumínio anodizado \\
\hline Nano-dureza [HV] & 79 & 266 \\
\hline Desvio-padrão & 10.2 & 132 \\
\hline
\end{tabular}

Observa-se pela Tabela 4 que as amostras anodizadas apresentaram um valor de dureza cerca de $350 \%$ superior ao exibido pelas amostras sem revestimento. Os resultados obtidos nos testes de nano-dureza encontram-se em uma faixa de valores relatados na literatura. Além disso, a Tabela 4 apresenta valores elevados de desvio-padrão.

As figs. 3.a e 3.b apresentam os comparativos das perdas volumétricas das amostras ensaiadas em desgaste. A fig. 3.a reúne os resultados de desgaste volumétrico médio das amostras testadas com tempo de duração de ensaio de $30 \mathrm{~min}$. E, na fig. 3.b, pode-se observar os valores médios de perda volumétrica das amostras testadas com tempo de duração de ensaio de 60 min. É importante ressaltar que todos os ensaios com as amostras anodizadas atingiram o substrato.

(a)

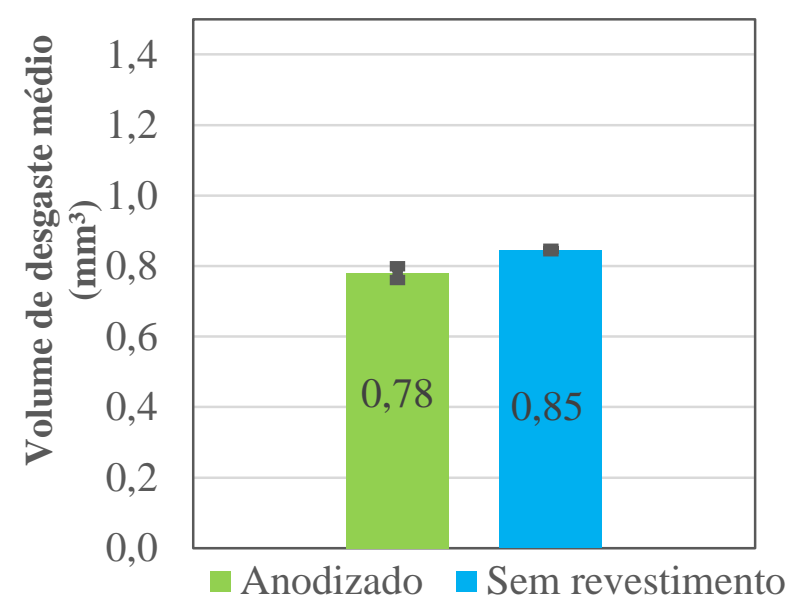

(b)

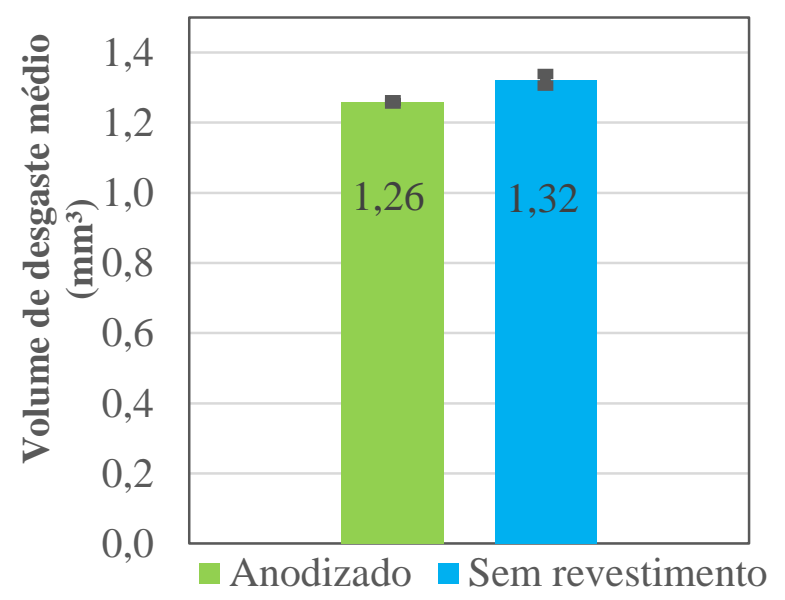

Figura 3: Comparativo do valor médio do volume de desgaste: (a) tempo de 30 min; (b) tempo de 60 min. 
Como pode ser observado na fig. 3.a, o processo de anodização proporcionou um suave aumento de $7.76 \%$ na resistência ao desgaste em relação às amostras de alumínio sem revestimento. É importante notar na fig. 3.a que os valores de desvio-padrão dos ensaios dessa série (expressos através das barras de erro) foram baixos, demonstrando a acurácia dos testes tribológicos realizados.

Um desempenho similar foi obtido nos ensaios de desgaste com duração de 60 min. Pela fig.3.b pode-se observar novamente que as amostras anodizadas apresentaram uma melhora pouco significativa na resistência ao desgaste em relação ao substrato (4.77\%). A acurácia dos ensaios tribológicos de desgaste novamente se manifesta nesta série de ensaios ao se observar as barras de erro na fig. 3.b.

Após as medições do volume de desgaste foi possível calcular as taxas de desgaste com o intuito de avaliar a agressividade do desgaste abrasivo para cada grupo de material, em cada série de ensaios, e também para compreender a evolução da taxa de desgaste com o tempo de duração dos ensaios. Dessa forma, as figs. 4.a e 4.b mostram os valores médios das taxas de desgaste das amostras relativos aos ensaios com duração de $30 \mathrm{~min}$ e $60 \mathrm{~min}$, respectivamente. Comparando os gráficos 4.a e 4.b observa-se que, aumentando o tempo de duração dos ensaios, as amostras anodizadas e de substrato apresentaram uma redução nos valores da taxa de desgaste de aproximadamente $20 \%$.

(a)

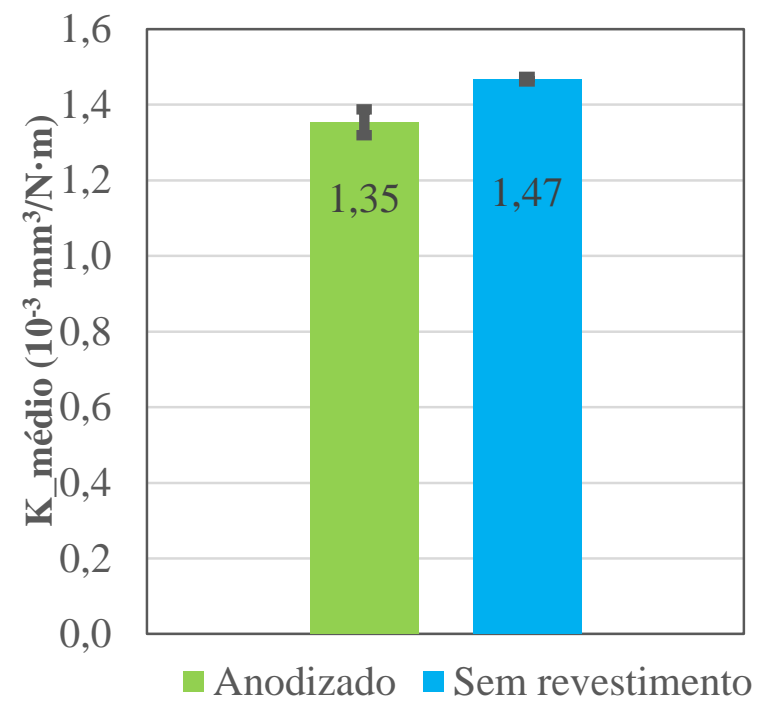

(b)

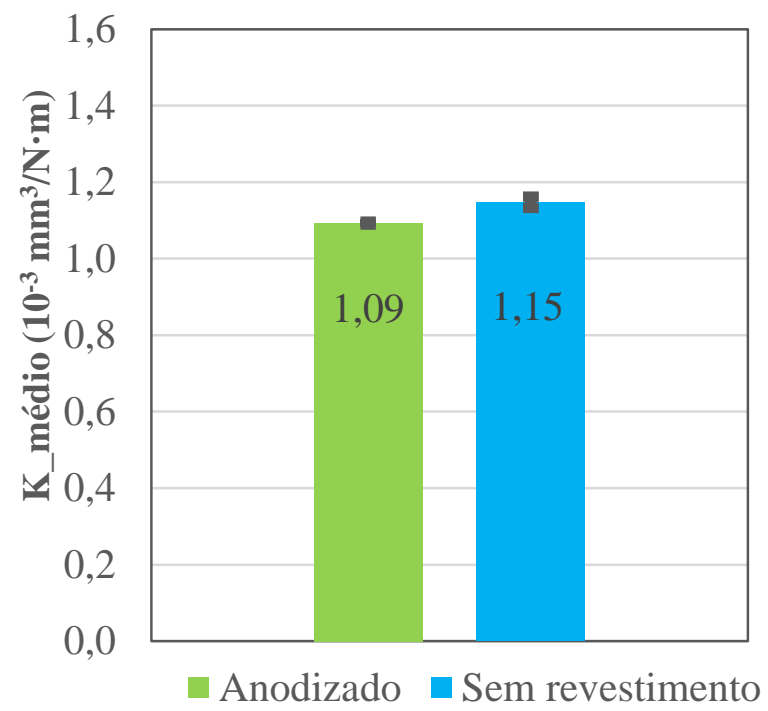

Figura 4: Comparativo do valor médio da taxa de desgaste: (a) tempo de $30 \mathrm{~min}$; (b) tempo de $60 \mathrm{~min}$. 


\section{Discussões}

Testes de dureza: Os resultados obtidos nos testes de nano-dureza confirmam as estimativas prévias (ver Tabela 4) [16]. No entanto, os valores de desvio-padrão de todas as medidas de dureza foram expressivamente elevados. No caso dos espécimes anodizados, a magnitude do desvio-padrão pode ser explicado pela densidade relativamente alta de poros na superfície, fato característico do processo de anodização. Dessa forma, testes de nano-indentação realizados em superfícies heterogêneas e porosas geralmente resultam em grande dispersão dos resultados. Resultados similares foram obtidos em outros trabalhos científicos envolvendo alumínio anodizado, e adotando a técnica da nano-indentação [17].

No caso das amostras de alumínio sem revestimento, as imperfeições microestruturais decorrentes do processo de fundição (dendritas, poros, diferenças de concentração de elementos de liga ao longo do volume do material, orientação dos grãos, dentre outros) foi a causa identificada para o elevado valor do desvio-padrão dos ensaios de nano-dureza. É importante ressaltar que o efeito de escala da ponta do indentador desempenha um papel importante em tais medições. Ou seja, caso fosse realizado um teste de dureza convencional aplicado à essas amostras, o desvio-padrão verificado seria provavelmente menor, já que a ponta do indentador é muito maior do que as diferenças microestruturais do material.

Testes de desgaste: Ao analisar o desgaste, a primeira correlação que pode ser feita é com a dureza da superfície ou do filme de revestimento. Segundo Zum Gahr [18], o coeficiente de desgaste de um material é inversamente proporcional à dureza. Partindo deste pressuposto, observa-se que os resultados apresentados no tópico anterior convergem para as expectativas. Pelas figuras de perda volumétrica e de taxa de desgaste das duas séries de ensaios (ver figs. 3 e 4), observa-se que as amostras de alumínio anodizado exibiram um aumento da resistência ao desgaste em relação às amostras do substrato. Porém, se considerarmos o valor da dureza das amostras anodizadas (ver Tabela 4), e comparar com o desempenho deste revestimento nos testes de desgaste, conclui-se que a resistência nos testes tribológicos está bastante aquém da dureza proporcionada pela modificação superficial.

Procurando elucidar os motivos para os comportamentos de resistência ao desgaste verificados neste trabalho foram realizadas análises da superfície das marcas de desgaste com microscopia confocal de varredura a laser. A fig. 5 mostra uma imagem representativa das características morfológicas das superfícies de desgaste de cada grupo de material das duas séries de ensaios. 
(a)

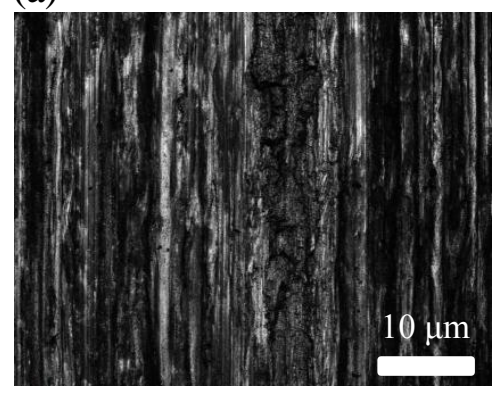

(b)

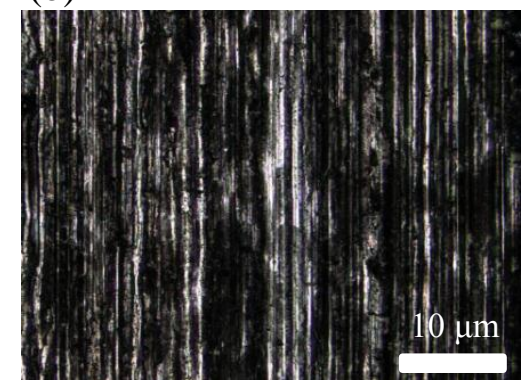

Figura 5: Aspecto da marca de desgaste dos ensaios tribológicos. (a) alumínio sem revestimento; (b) alumínio anodizado.

Dois modos de desgaste podem estar presentes em um sistema tribológico abrasivo: o desgaste abrasivo de dois corpos e o desgaste abrasivo de três corpos. Não é incomum uma mistura de ambos os modos, a depender das condições do tribosistema. No modo de desgaste abrasivo de dois corpos, as partículas ficam aderidas à uma ou às duas superfícies de contato, e vários sulcos de desgaste paralelos são produzidos na direção do deslizamento [19-21]. Dependendo do ângulo de ataque, a penetração da partícula abrasiva na superfície metálica do material pode resultar em microsulcamento ou microcorte. A característica do microsulcamento é o deslocamento do material à frente e para as laterais da partícula sem gerar desgaste. Já o microcorte provoca o deslocamento de material à frente da partícula e, neste caso, o ângulo de ataque favorece a perda de material [15].

As superfícies de desgaste das amostras anodizadas, e de forma similar para as amostras do substrato, apresentaram aspecto morfológico praticamente idêntico em todos os ensaios (ver fig. 5.a e fig. 5.b). Observou-se a predominância de mecanismos de desgaste abrasivo por deformação plástica, conforme indicado pelos vários sulcos de desgaste paralelos à direção do deslizamento. Assim, foram observadas características de abrasão pelos mecanismos de microcorte e microsulcamento, com predominância do microcorte.

Os resultados deste trabalho atestam a complexidade dos fenômenos de desgaste abrasivo apontando a influência de vários fatores sobre a taxa de desgaste. Em especial, o modo de desgaste e a dureza foram os fatores de maior impacto na durabilidade das superfícies testadas. No entanto, conforme explica Zum Gahr [15], outros fatores tem forte influência sobre o desgaste, tais como: a forma e o tamanho das partículas abrasivas, a microestrutura da amostra, a relação entre as durezas da amostra e da partícula abrasiva, dentre outros.

De fato, o presente trabalho comprovou a influência da dureza na resistência ao desgaste para os materiais ensaiados. Além disso, o modo de desgaste abrasivo de dois corpos, com predominância do mecanismo de microcorte, foi verificado tanto para os espécimes de alumínio 
anodizado quanto para os espécimes sem revestimento. Então qual seria a explicação para o suave aumento na resistência ao desgaste das amostras anodizadas (7.76 \% para o tempo de 30 $\min ;$ e $4.77 \%$ para o tempo de $60 \mathrm{~min}$ ), tendo em vista o valor de dureza exibido pelas mesmas? A explicação para tal fenômeno pode estar na condição de superfície das amostras anodizadas. Ou seja, enquanto as amostras de alumínio sem revestimento são planas e sólidas, as amostras anodizadas apresentam fissuras e poros decorrentes do processo de anodização [22]. No caso deste trabalho, a espessura da camada anodizada das amostras é de aproximadamente $20 \mu \mathrm{m}$. No processo de anodização apenas camadas de pequena espessura podem ser geradas sem a presença de poros. À medida que a espessura da camada de óxido aumenta, os poros são gerados permitindo a infiltração do eletrólito na direção do substrato do material e, dessa forma, o processo de anodização continua [22].

A porosidade superficial pode afetar a resistência ao desgaste de duas formas. Primeiramente, em função da razão do volume de material, a resistência ao desgaste de um material poroso é geralmente menor se comparada a de um material denso. Além disso, o material poroso é altamente propenso à fratura frágil. Conforme a dureza aumenta no processo de anodização, a tenacidade do material diminui. Assim, a combinação de baixa ductilidade e a presença de poros favorece a ocorrência de fratura frágil [23]. Segundo Hutchings [24], a taxa de desgaste de um material é significativamente maior na presença de falha por fratura frágil, tendo em vista o maior tamanho das partículas abrasivas e, consequentemente, a maior densidade das mesmas na interface de contato.

Outro fenômeno observado nos resultados dos ensaios experimentais foi uma maior taxa de desgaste das amostras anodizadas e de substrato no tempo de $30 \mathrm{~min}$, se comparado ao resultado da taxa de desgaste do mesmo grupo de material no tempo de $60 \mathrm{~min}$. Acredita-se que a causa desse fenômeno seja a fase inicial dos ensaios de desgaste, também conhecida como "runningin". Nesse período de "running-in", ou de estabilização do tribossistema, a rugosidade superficial desempenha um papel fundamental, pois é nessa fase inicial dos testes de desgaste que ocorre a suavização das asperezas do sistema corpo e contra-corpo [13, 25].

Dessa forma, as condições de superfície, bem como as condições tribológicas de contato, tem forte influência no comportamento do "running-in". Vários trabalhos relatam uma maior taxa de formação de detritos na interface de contato, com elevação na taxa de desgaste, e aumento do coeficiente de atrito [26-28]. Em uma fase posterior ao "running-in", geralmente segue-se a formação de uma tribocamada, e a estabilização do tribossistema ("steady-state”) [29]. 
É compreensível que o "run-in" tenha se manifestado de forma mais evidente nas amostras anodizadas e sem revestimento, tendo em vista as condições de superfície e as rugosidades exibidas pelas mesmas (ver Tabela 3). Além disso, o tempo de duração das duas séries de ensaios contribuiu para evidenciar os efeitos do "running-in" nos resultados da taxa de desgaste. Ou seja, estudos tem relatado os efeitos do "running-in" nos primeiros minutos dos ensaios de deslizamento, a depender das condições tribológicas. Mesmo consciente do caráter empírico do tempo no "run-in", estudos tem reportado um tempo de manifestação na faixa compreendida entre 2 e 10 min, e culminando na estabilização do sistema [25, 29]. Portanto, considerando o tempo de duração da série de ensaios com duração de 30 min, o efeito do "running-in" sobre a taxa de desgaste se torna muito mais notável que nos ensaios com duração de $60 \mathrm{~min}$.

\section{Conclusões}

Este trabalho consistiu no comparativo da resistência ao desgaste utilizando espécimes anodizados em um substrato de liga de alumínio SAE 305. Os resultados dos ensaios de desgaste permitiram concluir que:

1. Através de análise microscópica confocal de varredura a laser das superfícies de desgaste, verificou-se o modo de desgaste abrasivo de dois corpos para as amostras anodizadas e do substrato. De forma similar entre as amostras desses grupos de material, verificou-se a ocorrência de mecanismos de abrasão do tipo microsulcamento e microcorte, com a predominância deste último.

2. Apesar dos espécimes anodizados apresentarem um valor de dureza cerca de $350 \%$ maior que os espécimes sem revestimento, o aumento na resistência ao desgaste proporcionado pela anodização foi bastante suave. Esse comportamento pode ser explicado pela densidade de poro característico do processo de anodização.

3. A taxa de desgaste é fortemente dependente da rugosidade superficial do material durante a fase inicial do desgaste ("running-in"), conforme foi observado para as amostras anodizadas e do substrato. Torna-se importante uma melhor avaliação dos efeitos do "running-in" sobre o mesmo grupo de material em futuros trabalhos de desgaste. 


\section{Agradecimentos}

Os autores agradecem à Capes e ao programa brasileiro Ciência Sem Fronteiras, do CNPq, pelo suporte financeiro do projeto 401671/2013-5 e 314034/2013-7. Além disso, agradecemos à equipe do Laboratório de Tribologia e Materiais da Universidade Federal de Uberlândia, em especial ao doutorando José Lúcio Gonçalves Júnior, pelo apoio na realização dos ensaios experimentais.

\section{Referências}

1. Sabatini, G., Ceschini, L., Martini, C., Williams, J.A., and Hutchings, I.M. (2010). Improving sliding and abrasive wear behaviour of cast A356 and wrought AA7075 aluminium alloys by plasma electrolytic oxidation. Materials \& Design 31, 816-828.

2. Malayoglu, U., Tekin, K.C., Malayoglu, U., and Shrestha, S. (2011). An investigation into the mechanical and tribological properties of plasma electrolytic oxidation and hard-anodized coatings on 6082 aluminum alloy. Materials Science and Engineering: A $528,7451-7460$.

3. Tseng, C.-C., Lee, J.-L., Kuo, T.-H., Kuo, S.-N., and Tseng, K.-H. (2012). The influence of sodium tungstate concentration and anodizing conditions on microarc oxidation (MAO) coatings for aluminum alloy. Surface and Coatings Technology 206, 34373443.

4. Fadel, A.A. (2010). Avaliação do efeito do tracionamento em elevados níveis de EDS sobre a resistência em fadiga do condutor IBIS (CAA 397,5 MCM). In Departamento de Engenharia Mecânica, Volume Doutorado. (ENM. TD - 05/2010: Universidade de Brasília), p. 185.

5. Fadel, A.A., Rosa, D., Murça, L.B., Fereira, J.L.A., and Araújo, J.A. (2012). Effect of high mean tensile stress on the fretting fatigue life of an Ibis steel reinforced aluminium conductor. International Journal of Fatigue 42, 24-34.

6. A. A. Voevodin, A.L.Y., V. V. Lyubimov, M. S. Donley, J. S. Zabinski (1996). Characterization of wear protective Al-Si-0 coatings forrned on Al-based alloys by micro-arc discharge treatment. Surface and Coatings Technology 86-87, 516-521. 
7. Burakowiski, T., and Wierzchón, T. (1999). Surface Engineering of Metals - Principles, Equipment and Technologies., Volume I, (London).

8. Krishna, L.R., Purnima, A.S., and Sundararajan, G. (2006). A comparative study of tribological behavior of microarc oxidation and hard-anodized coatings. Wear 261, 1095-1101.

9. Pritchard, C., and Robinson, P.R. (1969). Abrasion resistence of hard anodized aluminum. Wear 13, 361-368.

10. Campbell, W.J. (1967). Anodic finishes for wear resistance. In Anodisong Aluminium, A.D. Association, ed. (Nottingham: Paper II).

11. Cirik, E., and Genel, K. (2008). Effect of anodic oxidation on fatigue performance of 7075-T6 alloy. Surface and Coatings Technology 202, 5190-5201.

12. Technologies, S.M. (2005). Anodized Aluminum Application. (http://www.superiormetals.us/anodized-aluminum.htm: Superior Metal Technologies).

13. Holmberg, K., and Matthews, A. (1998). Coatings Tribology - Properties, Techniques and Applications in Surface Engineering Volume 28, (Gt Britain: Dowson, D.).

14. Gee, M.G., Gant, A.J., Hutchings, I.M., Kusano, Y., Schiffman, K., Acker, K.V., Poulat, S., Gachon, Y., Stebut, J.v., Hatto, P., et al. (2005). Results from an interlaboratory exercise to validate the micro-scale abrasion test. Wear 259, 27-35.

15. Zum Gahr, K.-H. (1998). Wear by Hard Particles. Tribology International 31, 587-596.

16. Steier, V.F.P., M. S. T.; Doca, T. (2016). The influence of diamond-like carbon and anodized aluminum oxide coatings on wear of aluminum alloy. Submitted to Tribology International.

17. Datcheva, M., Cherneva, S., Stoycheva, M., Iankov, R., and Stoychev, D. (2011). Determination of Anodized Aluminum Material Characteristics by Means of Nanoindentation Measurements. Materials Sciences and Applications 2, 1452-1464.

18. Gahr, K.H.Z. (1988). Modelling of twoo-body abrasive wear. Wear 124, 87-103.

19. Adachi, K., and Hutchings, I.M. (2005). Sensitivity of wear rates in the micro-scale abrasion test to test conditions and material hardness. Wear 258, 318-321. 
20. Adachi, K., and Hutchings, I.M. (2003). Wear-mode mapping for the micro-scale abrasion test. Wear 255, 23-29.

21. Samuels, L.E., and Mulhearn, T.O. (1962). The abrasion of metals: a model of the process. Wear 5, 478-498.

22. Henley, V.F. (1982). Anodic oxidation of aluminum and its alloys. Pergamon Press, UK Spring, $150 \mathrm{pp}$.

23. Guezmil, M., Bensalah, W., Khalladi, A., Elleuch, K., Depetris-Wery, M., and Ayedi, H.F. (2015). Friction coefficient and microhardness of anodized aluminum alloys under different elaboration conditions. Transactions of Nonferrous Metals Society of China $25,1950-1960$.

24. Hutchings, I.M. (1992). Tribology - Friction and Wear of Engineering Materials, 1 Edition, (London: Edward Arnold).

25. Horng, J.-H.L., M-L. (2002). The contact characteristics of rough surfaces in line contact during running-in process. Wear 253, 899-913.

26. Hanief, M., and Wani, M.F. (2016). Effect of surface roughness on wear rate during running-in of En31-steel: Model and experimental validation. Materials Letters 176, 9193.

27. Ribeiro, F.R.V. (2012). Estudo do comportamento tribologico de filmes DLC dopados com Ag. In Departamento de Engenharia Mecânica, Volume Mestre. (Coimbra: Faculdade de Ciências e Tecnologia da Universidade de Coimbra), p. 55.

28. Wang, Z., and Zhou, Q. (2012). Applying a population growth model to simulate wear of rough surfaces during running-in. Wear 294-295, 356-363.

29. Costa, R.P.d.C. (2010). Estudo de lubrificação híbrida usando filmes de DLC com lubrificantes nas áreas espacial, automotiva e médica. In Departamento de PósGraduação em Engenharia e Tecnologia Espaciais/Ciência e Tecnologia de Materiais e Sensores, Volume Doutorado. (São José dos Campos: Instituto Nacional de Pesquisas Espaciais - INPE), p. 146. 